Supplementary Information

\title{
Determination of Serotonin Concentration in Single Human Platelets through Single-Entity Electrochemistry
}

\author{
Jungeun Lee, ${ }^{\dagger}$ Yeji Kang, ${ }^{\dagger}$ Jinho Chang, ${ }^{\ddagger}$ Jaewoo Song, ${ }^{*}$ § and Byung-Kwon Kim ${ }^{*}, \dagger$ \\ †Department of Chemistry, Sookmyung Women's University, Seoul 04310, Republic of Korea \\ ‡Department of Chemistry and Research Institute for Convergence of Basic Sciences, Hanyang University, \\ Seoul 04763, Republic of Korea \\ ${ }^{\S}$ Department of Laboratory Medicine, Yonsei University College of Medicine, Severance Children's Hospital, \\ Seoul 03722, Republic of Korea
}

${ }^{*}$ Corresponding authors: Jaewoo Song, and Byung-Kwon Kim

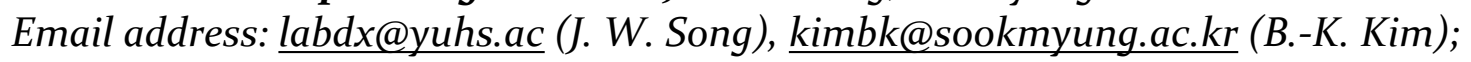




\section{Table of Contents}

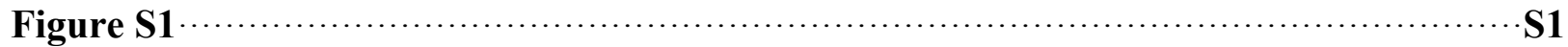

CVs of the Platelet-related samples using a $25 \mu \mathrm{m}$ Pt UME or $2 \mathrm{~mm}$ Pt disk electrode.

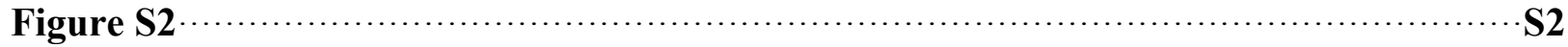

i-t curves of PRP in RLB at a $25 \mu \mathrm{m}$ Pt UME under applied potentials of +0.2 and $+0.5 \mathrm{~V}$.

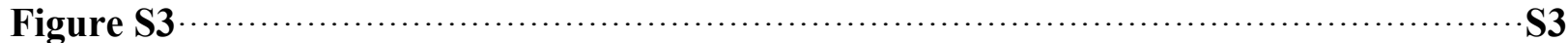

i-t curves of PRP, PPP, and RRP in NS solution with a Pt UME.

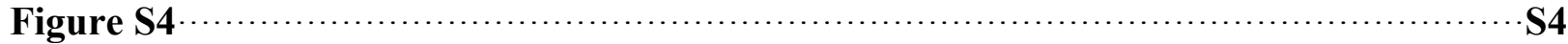

i-t curves of PPP, 10.0, 20.1, 40.2, and $100 \mathrm{fM}$ platelets in NS at a Pt UME.

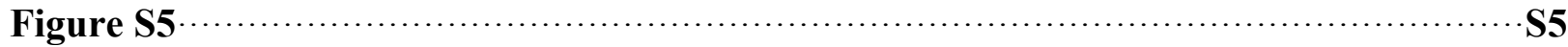

Complete blood count (CBC) obtained from the Advia2120i Auto Hematology Analyzer.

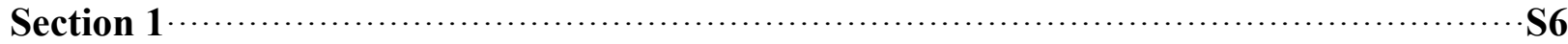

Different shaped spikes in the i-t curves.

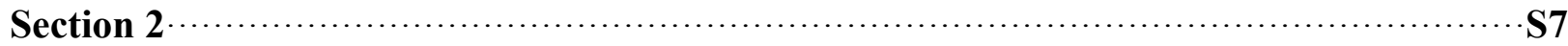

Signal determination considering $\mathrm{S} / \mathrm{N}$ ratio at a current event.

Section $3 \cdots$

Serotonin analysis of platelets through the assumption that it is $100 \%$ oxidized. 

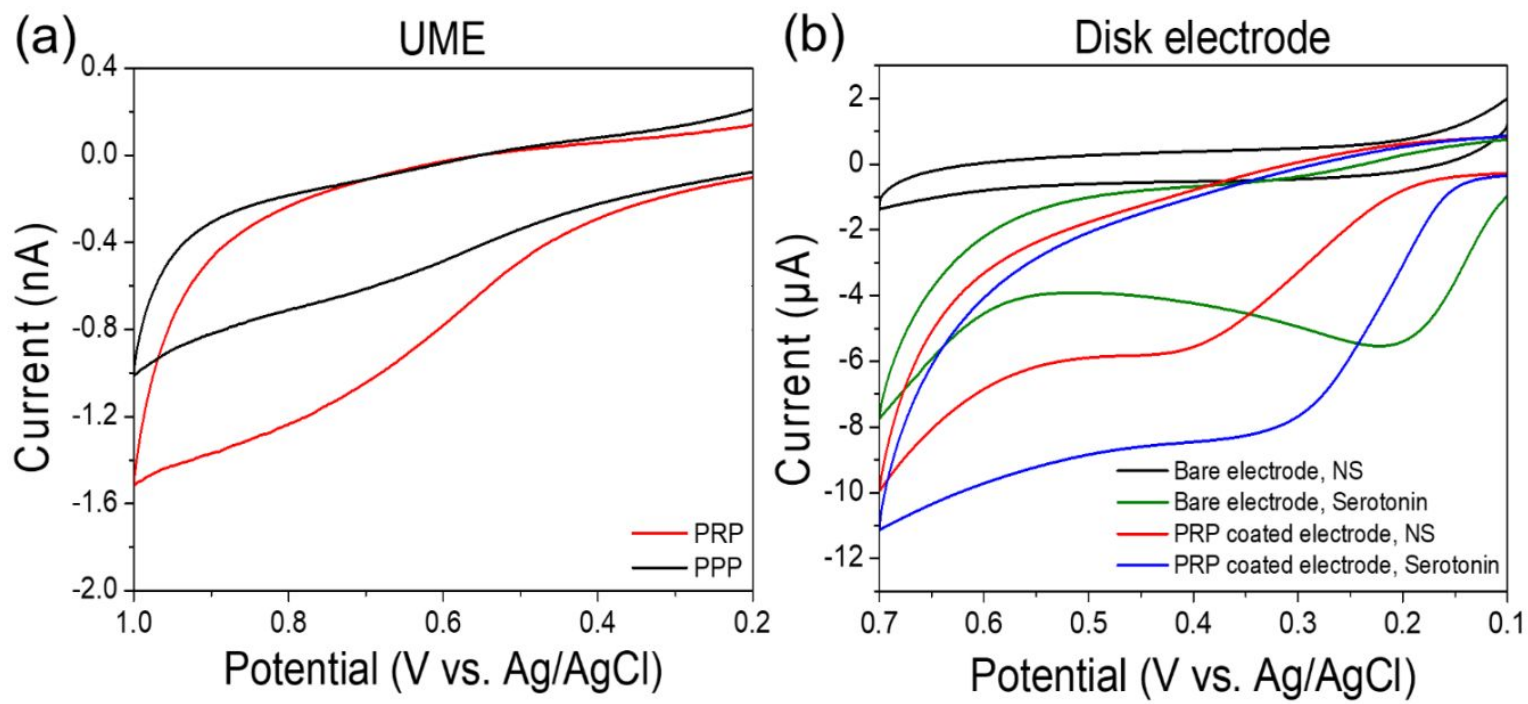

Figure S1. (a) CVs of PPP (black line) and PRP (red line) with a $25 \mu \mathrm{m}$ Pt UME at a scan rate of $50 \mathrm{mV} / \mathrm{s}$. (b) CVs of the bare (black line) and PRP coated (red line) disk electrode in NS solution. CVs of the bare (green line) and PRP coated (blue line) disk electrode in $2 \mathrm{mM}$ serotonin solution. The scan rate is $50 \mathrm{mV} / \mathrm{s}$, and the diameter of the disk electrode is $2 \mathrm{~mm}$. The PRP sample was dropped and dried on the disk electrode surface several times, and then the electrode was immersed in NS or $2 \mathrm{mM}$ serotonin solution. 


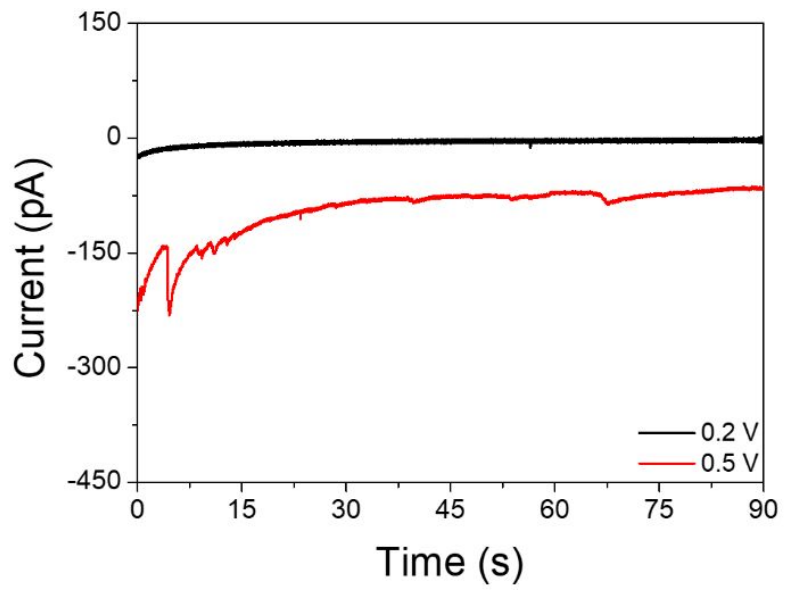

Figure S2. $i$-t curves of PRP in RLB at Pt UME ( $25 \mu \mathrm{m}$ diameter $)$ under applied potentials of +0.2 and $+0.5 \mathrm{~V}$ (vs. $\mathrm{Ag} / \mathrm{AgCl}$ ). It was measured by changing only the applied voltage in the same solution with a final platelet concentration of $10.0 \mathrm{fM}$. 


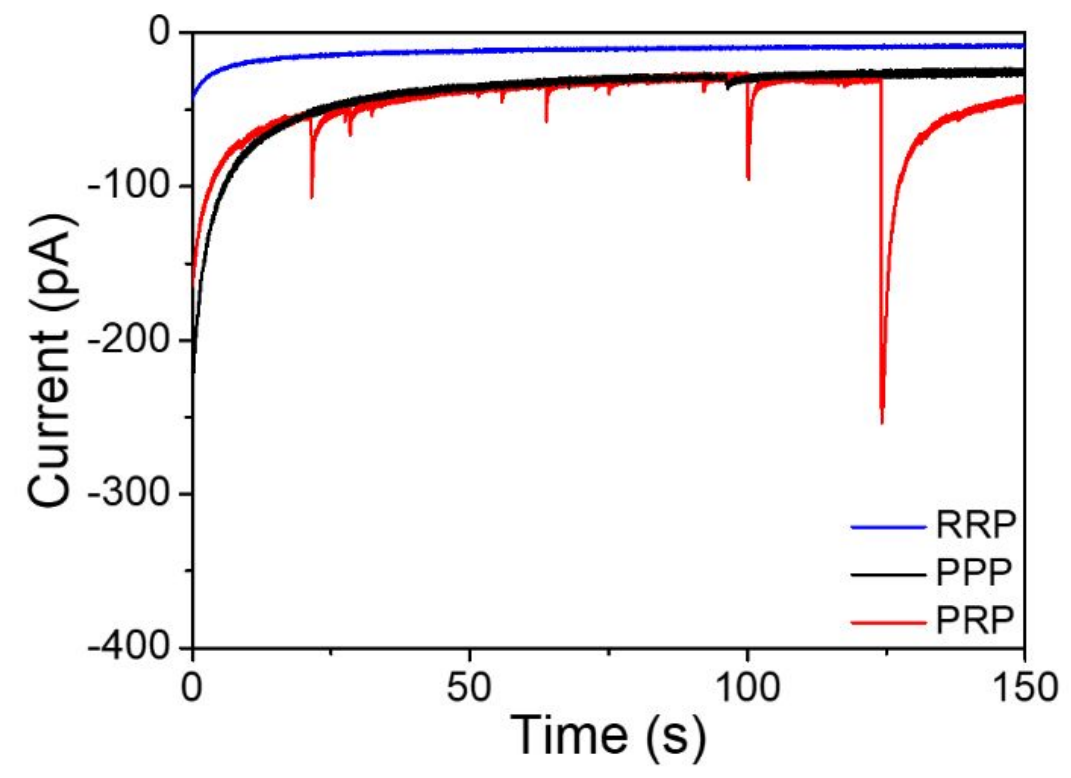

Figure S3. i-t curves of PRP (100 fM of platelets, red line), PPP (black line), and RRP (blue line) in NS with a Pt UME at $+0.5 \mathrm{~V}$. 


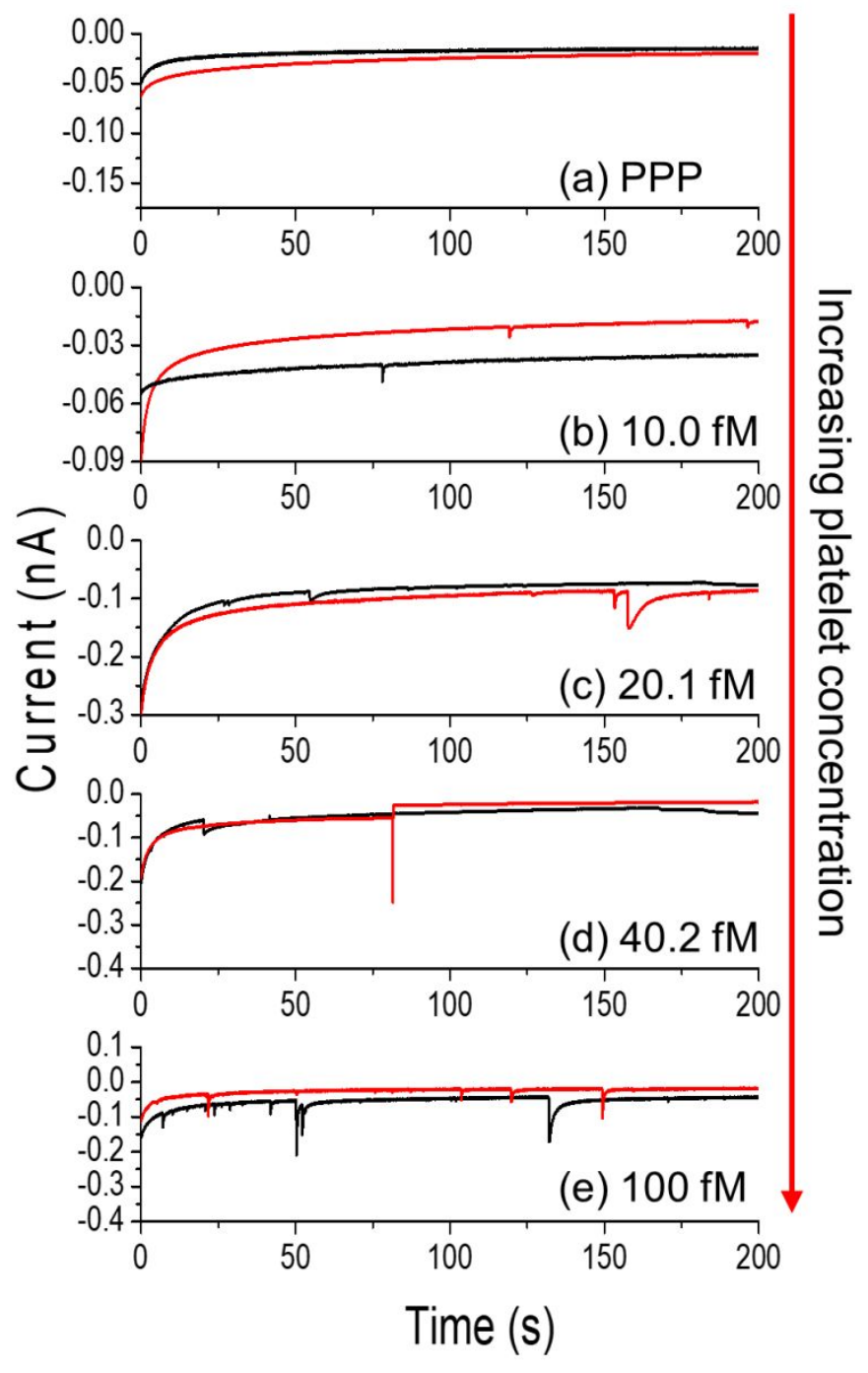

Figure S4. i-t curves of (a) PPP, (b) 10.0, (c) 20.1, (d) 40.2, and (e) $100 \mathrm{fM}$ platelets in NS at a Pt UME. 


\begin{tabular}{|c|c|c|c|}
\hline \multicolumn{4}{|c|}{ Routine $\mathrm{CBC}$} \\
\hline WBC & $\mathrm{L}$ & 0.08 & $\times 10^{3}$ cells $/ \mu \mathrm{L}$ \\
\hline $\mathrm{RBC}$ & $\mathrm{L}$ & 0.05 & * $\times 10^{6}$ cells $/ \mathrm{uL}$ \\
\hline $\mathrm{HGB}$ & $\bar{L}$ & 0.2 & * $\mathrm{g} / \mathrm{dL}$ \\
\hline $\mathrm{HCT}$ & $\mathrm{L}$ & 0.4 & ${ }^{*} \%$ \\
\hline MCV & & 89.7 & ${ }^{*} \mathrm{fL}$ \\
\hline $\mathrm{MCH}$ & $\mathrm{H}$ & 45.1 & * $\mathrm{pq}$ \\
\hline $\mathrm{MCHC}$ & $\mathrm{H}$ & 50.3 & $\mathrm{~g} / \mathrm{dL}$ \\
\hline $\mathrm{CHCM}$ & & 35.1 & $* \mathrm{~g} / \mathrm{dL}$ \\
\hline $\mathrm{CH}$ & & 31.5 & $* \mathrm{pg}$ \\
\hline RDW & $H$ & 15.1 & $* \%$ \\
\hline HDW & & 3.12 & 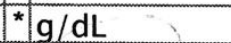 \\
\hline KPLT & $\mathrm{H}$ & 832 & * $\times 10^{3}$ cells $/ \mu \mathrm{L}$ \\
\hline MPV & $\mathrm{L}$ & 7.1 & * $\mathrm{fL}$ \\
\hline
\end{tabular}

Figure S5. Complete blood count (CBC) obtained from the Advia2120i Auto Hematology Analyzer. 
Section 1. Different shaped spikes in the i-t curves.

The spikes observed in the i-t curves can vary depending on the size, concentration, and contact area of the particles colliding with the electrode. For example, if the contact area (between the electrode and platelet) is large, the rate of electrochemical reaction increases, and a sharp oxidation peak is observed as a result. Conversely, if the contact area is small, the rate of electrochemical reaction decreases, and a broad decay peak is observed. Therefore, the shapes of the current spikes differ depending on these factors. These varied-shaped spikes have also been reported by Bard's group $^{1-3}$, Compton's group ${ }^{4-6}$, and Ewing's group ${ }^{7,8}$. 
Section 2. Signal determination considering $\mathrm{S} / \mathrm{N}$ ratio at a current event.

To confirm the collision events (platelet collisions), the background fluctuations of current were analyzed. We have selected more than 20 current points that have the highest difference in current pitch in a time range $(10 \mathrm{~s})$. For example, the average $(-28.5 \mathrm{pA})$ and standard deviation (SD, 1.34 pA) of these current values were obtained from data shown in Figure S6. We considered a change in current greater than three times this standard deviation (3SD, $4.02 \mathrm{pA}$ ) as a collision. In this experiment, it was rarely difficult to judge whether a collision occurred ( $\geq 4.02 \mathrm{pA})$.

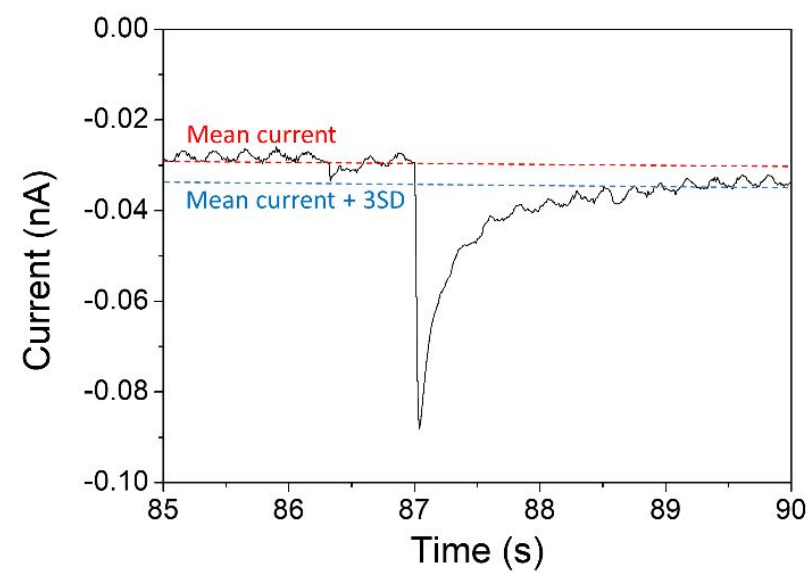

Figure S6. An example of spike signal determination considering $\mathrm{S} / \mathrm{N}$ ratio. 
Section 3. Serotonin analysis of platelets through the assumption that it is $100 \%$ oxidized.

Measuring the percentage of the actually oxidized serotonin in platelets is not easy. This is because platelets are not synthetic samples but are obtained from actual human blood. However, in many previous SEE studies (although they report the results of emulsions and liposomes), most of the electrochemical redox materials inside a single particle react at the electrode ${ }^{1,2,9,10}$. With this assumtion, quantification analysis of redox materials inside single particle using Eq. S1 is a common approach in SEE experiments.

$d_{\text {particle }}=2 \sqrt[3]{\frac{3 Q}{4 \pi F C_{\text {red }}}}$

Eq. S1

Here, $\mathrm{Q}$ is the measured charge, $\mathrm{F}$ is the Faraday constant, $\mathrm{C}_{\mathrm{red}}$ is the concentration of redox species, and $\mathrm{d}_{\text {particle }}$ is dimeter of the particle. When applying this equation, it is assumed that all the redox substances in the particles are oxidized. The results obtained using this equation agree well with the diameter of the particles $\left(\mathrm{d}_{\text {particle }}\right)$ obtained from dynamic light scattering (DLS) experiments. Therefore, the same assumptions were applied in this study. 


\section{References}

(1) Kim, B.-K.; Boika, A.; Kim, J.; Dick, J. E.; Bard, A. J. Characterizing Emulsions by Observation of Single Droplet Collisions-Attoliter Electrochemical Reactors. J. Am. Chem. Soc. 2014, 136 (13), 4849-4852.

(2) Kim, B.-K.; Kim, J.; Bard, A. J. Electrochemistry of a Single Attoliter Emulsion Droplet in Collisions. J. Am. Chem. Soc. 2015, 137 (6), 2343-2349.

(3) Dick, J. E.; Renault, C.; Bard, A. J. Observation of Single-Protein and DNA Macromolecule Collisions on Ultramicroelectrodes. J. Am. Chem. Soc. 2015, 137 (26), 8376-8379.

(4) Cheng, W.; Compton, R. G. Quantifying the Electrocatalytic Turnover of Vitamin B12Mediated Dehalogenation on Single Soft Nanoparticles. Angew. Chemie - Int. Ed. 2016, 55 (7), 2545-2549.

(5) Laborda, E.; Molina, A.; Espïn, V. F.; Martïnez-Ortiz, F.; Garcïa de la Torre, J.; Compton, R. G. Single Fusion Events at Polarized Liquid-Liquid Interfaces. Angew. Chemie - Int. Ed. 2017, 56 (3), 782-785.

(6) Laborda, E.; Molina, A.; Batchelor-McAuley, C.; Compton, R. G. Individual Detection and Characterization of Non-Electrocatalytic, Redox-Inactive Particles in Solution by Using Electrochemistry. ChemElectroChem 2018, 5 (3), 410-417.

(7) Dunevall, J.; Fathali, H.; Najafinobar, N.; Lovric, J.; Wigström, J.; Cans, A. S.; Ewing, A. G. Characterizing the Catecholamine Content of Single Mammalian Vesicles by CollisionAdsorption Events at an Electrode. J. Am. Chem. Soc. 2015, 137 (13), 4344-4346.

(8) Li, X.; Ren, L.; Dunevall, J.; Ye, D.; White, H. S.; Edwards, M. A.; Ewing, A. G. Nanopore Opening at Flat and Nanotip Conical Electrodes during Vesicle Impact Electrochemical Cytometry. ACS Nano 2018, 12 (3), 3010-3019.

(9) Zhou, X. F.; Cheng, W.; Compton, R. G. Doping of Single Polymeric Nanoparticles. Angew. Chemie - Int. Ed. 2014, 53 (46), 12587-12589. 
(10) Cheng, W.; Compton, R. G. Investigation of Single-Drug-Encapsulating Liposomes Using the Nano-Impact Method. Angew. Chemie Int. Ed. 2014, 53 (50), 13928-13930. 